\title{
Improvement and Analysis of Fatigue Strength for Mild Steel 20MnCrS5 during Carburizing and Quenching
}

\author{
Shan MIAO ${ }^{1}$, Jiangang WANG ${ }^{2}$, Dongying $\mathrm{JU}^{2,3 *}$, Huijun $\mathrm{ZHAO}^{4}$, Mengyuan $\mathrm{YAN}^{1}$ \\ ${ }^{1}$ Graduate School of Saitama Institute of Technology, Fusaiji 1690, Fukaya, Saitama 369-0293, Japan \\ ${ }^{2}$ Hebei Key Laboratory of Material Near-Net Korming Technology, Hebei University of Science and Technology, \\ Shijiazhuang Hebei 050018, China \\ ${ }^{3}$ Department of Material Science and Engineering, Saitama Institute of Technology, Fusaiji 1690, Fukaya, Saitama 369- \\ 0293, Japan \\ ${ }^{4}$ School of Mechanical Engineering, Hangzhou Dianzi University, Hangzhou, 310018, China \\ crossref http://dx.doi.org/10.5755/j01.ms.26.2.22175
}

Received 05 December 2018; accepted 27 January 2019

\begin{abstract}
Distortion and fatigue are both important criteria for evaluating carburizing and quenching process. An optimized process was proposed to reduce distortion and improve fatigue strength simultaneously. Mild steel 20MnCrS5 were heat treated using standard condition and optimized condition respectively. The microstructure, hardness, residual stress, domain size, fatigue performance and crack growth rate with different conditions were studied. Due to carburization, the near surface of the materials have different microstructures with different carbon concentration. The carburized layer, subsurface layer and central layer were selected to prepare the fatigue specimens and to be evaluated. The strengthening effect was verified by comparing the fatigue limit and the crack growth rate. The strengthening mechanism was analyzed by comparing microstructure, retained austenite, residual stress and domain size. The results show that with the optimized condition the fatigue performance at different layers are improved while achieving higher surface hardness. The joint action of domain refinement, more compressive residual stress and less retained austenite results in the strengthening.

Keywords: carburizing and quenching, fatigue, crack growth rate, residual stress, domain size.
\end{abstract}

\section{INTRODUCTION}

Since failure caused by re - peated loading accounts for at least half of all mechanical failures, the fatigue performance is prime importance for the materials, which are subject to cyclic loading [1,2]. Carburizing and quenching process is widely used in industry, as a method of surface hardening technology to obtain improved mechanical properties and fatigue strength of mechanical components, such as gears, shafts and so on [3-5]. The main advantages of carburizing are that they can achieve high surface hardness, compressive residual stress and good toughness at the core, which can effectively improve the surface strength, wear resistance and fatigue strength of the steel [6-8].

It is well known that many performances can affect the fatigue resistance of carburized parts. One of the important performances is the distribution of residual stresses [9]. The compressive residual stresses counteract the applied tensile stresses and therefore improve the fatigue performance. The ideal hardness distribution shifts the failure initiation point transfer from the core to the surface. Therefore, in order to obtain maximum gain in fatigue resistance, the hardness distribution should be kept in a certain range depending on the thickness and size of the specimen [10]. Core microstructure is also one of these performances. Lower carbon content of core increases the fatigue resistance, particularly due to the enlarged compressive residual stresses at the surface, compared with the cases of higher carbon content [11]. The refinement of austenitic grain size is also one of these performances, which results in a fine martensitic structure and/or reduced size and density of micro cracks in the structure produce better fatigue resistance $[12,13]$. Many factors such as carburizing time and temperature during the various stages of a carburizing process affect the performance above $[14,15]$. It is necessary to determine the relationship between the carburizing process factors and the material performances.

In this research, an optimized carburizing and quenching process is proposed to improve fatigue strength of 20MnCrS5 steel. The strengthening mechanism is analyzed by comparing microstructure, retained austenite, residual stress and domain size.

\section{EXPERIMENTAL PROCEDURE}

\subsection{Heat treatment process}

Increasing the carburizing temperature and carburizing time will reinforce the carburizing effect but increase domain growth and distortion. On the other hand, insufficient carburizing depth and surface carbon phenomenon occurs with low carburizing temperature and short carburizing time $[16,17]$. Therefore, the method of carburizing with high-carbon potential and low temperature diffusion is used to solve this contradiction. Heat treatment condition A shown in Fig. $1 \mathrm{a}$ is a standard carburizing and quenching process which is often used. Heat treatment

\footnotetext{
${ }^{*}$ Corresponding author. Tel.: +81-48-585-6902; fax: +81-48-585-5928.

E-mail address: dyju@sit.ac.jp (D.Y.Ju)
} 
condition B shown in Fig. $1 \mathrm{~b}$ reduces carburization time and increases diffusion time. It is summarized from the previous optimization work it can achieve minimal distortion [18].

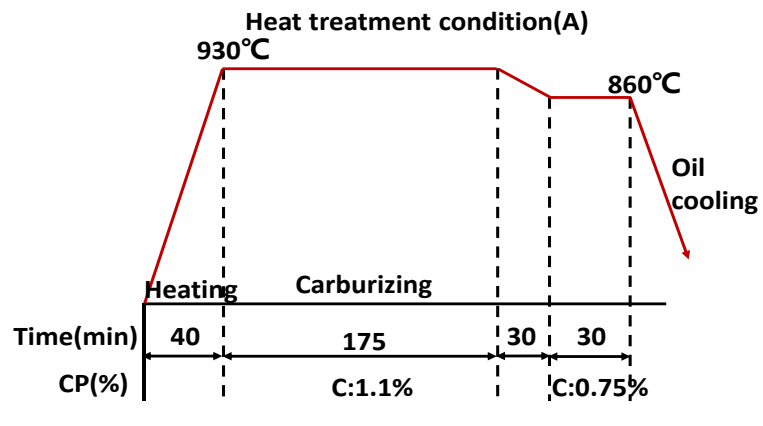

a

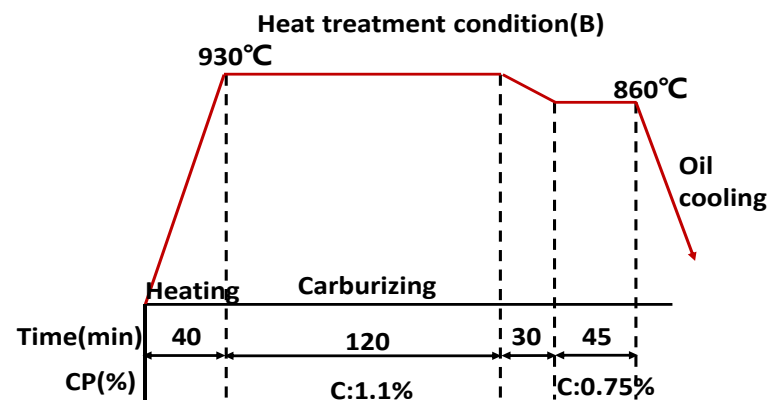

b

Fig. 1. Heat treatment conditions: a-standard condition; $\mathrm{b}$-optimized condition

\subsection{Material and preparation specimens}

A finite element program called COSMAP is developed to predict the temperature field, carbon diffusion, phase transformation, hardness and residual stress during carburizing and quenching process [19]. The size of the specimens is $50 \mathrm{~mm} \times 50 \mathrm{~mm} \times 80 \mathrm{~mm}$. The total nodes and elements of model are 9261 and 8000, respectively. Fine meshes concentrate on the surface of the specimen and are used to improve the calculation accuracy where there are steep thermal, stress and carbon gradients.

The chemical compositions of the $20 \mathrm{MnCrS} 5$ steel is shown in Table 1. The results of the simulation at surface and cross section are shown in Fig. 2. The distribution gradient of the carbon content from surface to the core due to the carbon diffusion can be observed. At the surface, the carbon content reaches $0.75 \%$. Inside the specimen, the carbon content still keeps low. In addition, the carburizing depth is about $800 \mu \mathrm{m}$. The differences of the carbon content from surface to core after carburizing process has a great effect on the phase transformations and result in martensite layer with a high hardness. The distribution gradient of the hardness and residual stress from surface to the inside can also be observed.

Table 1. The chemical compositions of $20 \mathrm{MnCrS5}$ steel by wt. $\%$

\begin{tabular}{|c|c|c|c|c|c|}
\hline Material & $\mathrm{C}$ & $\mathrm{Si}$ & $\mathrm{Mn}$ & $\mathrm{Cr}$ & $\mathrm{Mo}$ \\
\hline $20 \mathrm{MnCrS5}$ & 0.2 & 0.2 & 1.2 & 1.2 & - \\
\hline
\end{tabular}

According to the results of simulation, the carburized layer, subsurface layer and central layer are selected as representative parts to be sliced from the specimens as shown in Fig. 3.

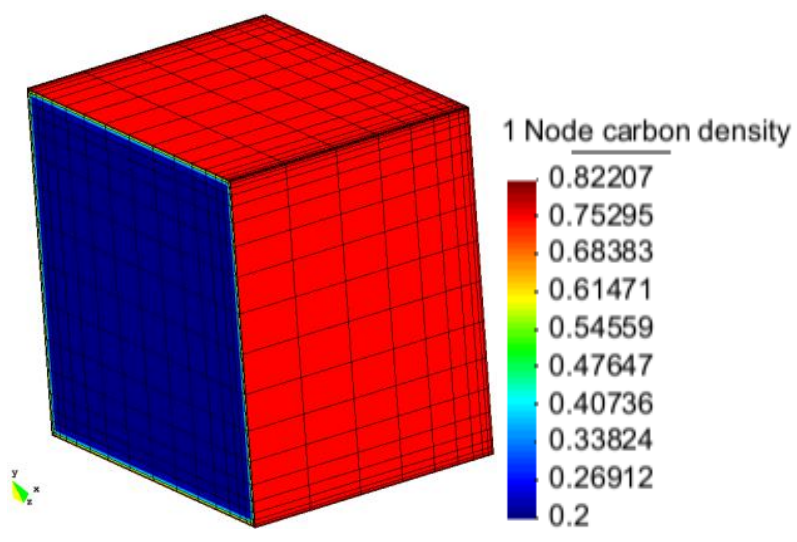

a

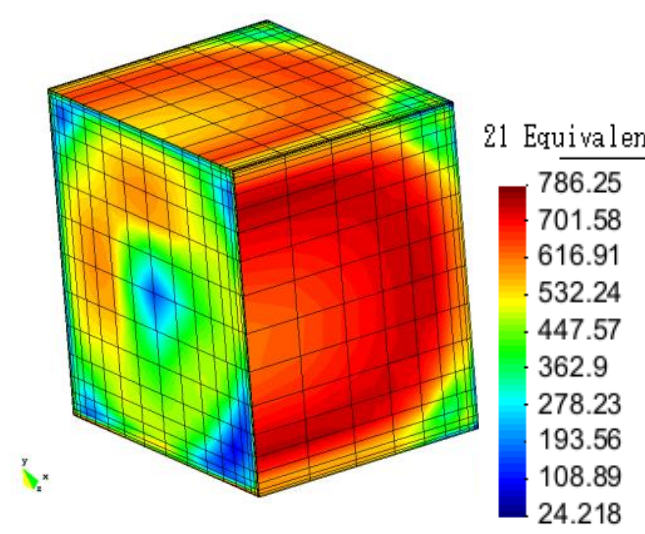

b

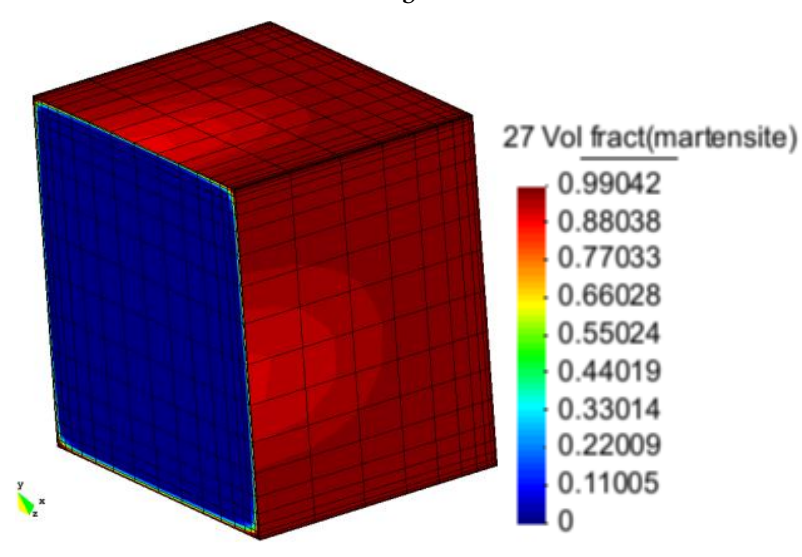

c

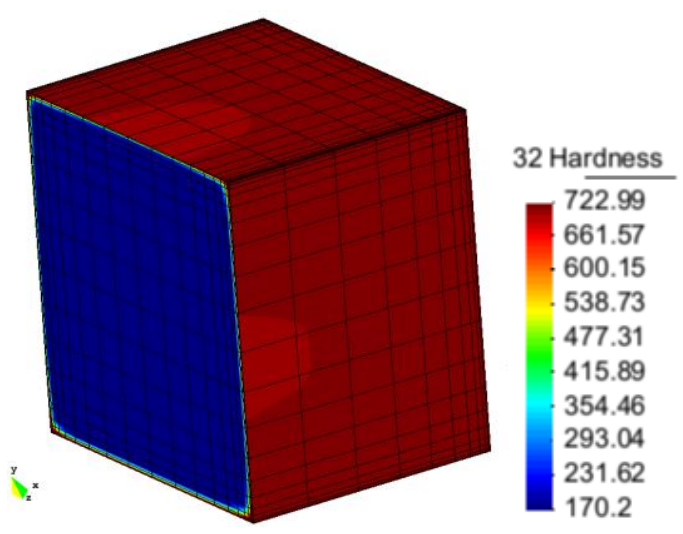

d

Fig. 2. Simulation during carburizing and quenching: a-distribution of carbon; b-distribution of equivalent stress; c-distribution of martensite; d-distribution of hardness 




Fig. 3. Method of slicing and measuring

\section{RESULTS AND DISCUSSION}

\subsection{Microstructure}

The cross section of the specimens was first grounded and polished and then the surfaces of the microstructure observation points are eroded with a solution of $4 \% \mathrm{HNO}_{3}+96 \% \mathrm{C}_{2} \mathrm{H}_{5} \mathrm{OH}$, the microstructures at different depth from the surface are finally observed by OM.

The measured results show good agreement with the simulated results. As shown in Fig. $4 \mathrm{a}$ and Fig. $4 \mathrm{~b}$ the microstructure of carburized layer after carburizing and quenching are mainly acicular martensite, retained austenite and fine carbide particles. It can be observed that Fig. 4 b has finer microstructure and less retained austenite. Since the diffusion time of condition B is increased, it facilitates the precipitation of carbon in the retained austenite with the form of carbide. It caused a decrease in the stability of the austenite, which was beneficial to the transformation of the retained austenite. Hence, the decrease of the retained austenite led to a harder surface. As shown in Fig. $4 \mathrm{c}$ and Fig. $4 \mathrm{~d}$, the microstructure is to form pearlite structure at central layers. Besides the pearlite structure, small portions of other phases, such as bainite are present. They can retain the strength and toughness of the core. It can be considered that the microstructure with condition $\mathrm{B}$ is more beneficial to improve the wear resistance and fatigue strength than that by using the conventional way.

\subsection{Surface hardness}

In order to investigate the distribution of the hardness, Vickers hardness is measured of the specimens with different heat treatment conditions. The test force is selected at $49 \mathrm{~N}$. Each result is the average value of three measurements.

The hardness distribution of specimens with different conditions is shown in Fig. 5. The measured results show good agreement with the simulated results. The carburizing and quenching processes increase the hardness to meet the requirement for carburizing and quenching production.

As is well known, the retained austenite is inversely proportional to the hardness [20]. Hence the hardness with condition $\mathrm{B}$ is higher due to the smaller volume fraction of retained austenite although it is theoretically estimated that the carbon content of the condition A is higher.

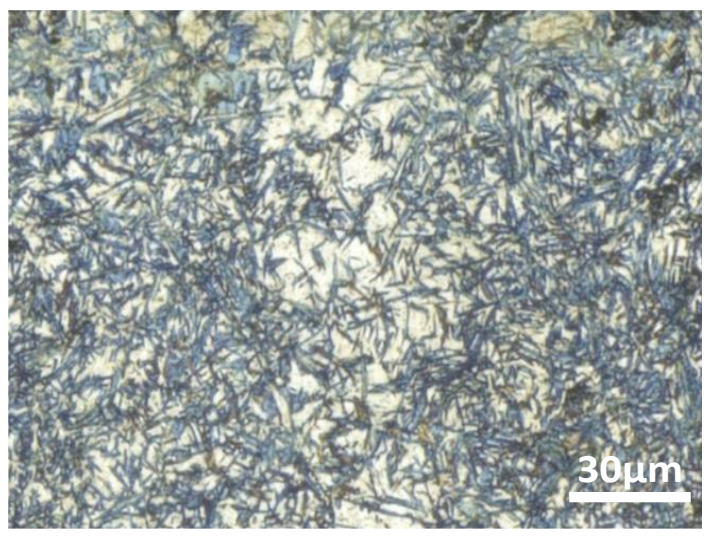

$\mathrm{a}$

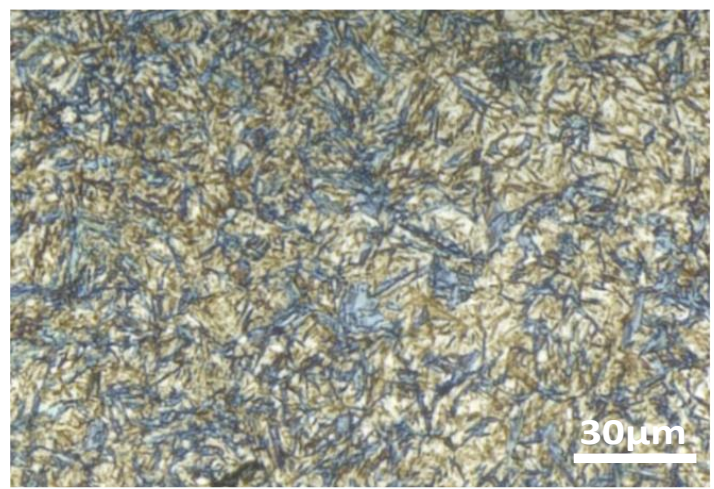

b
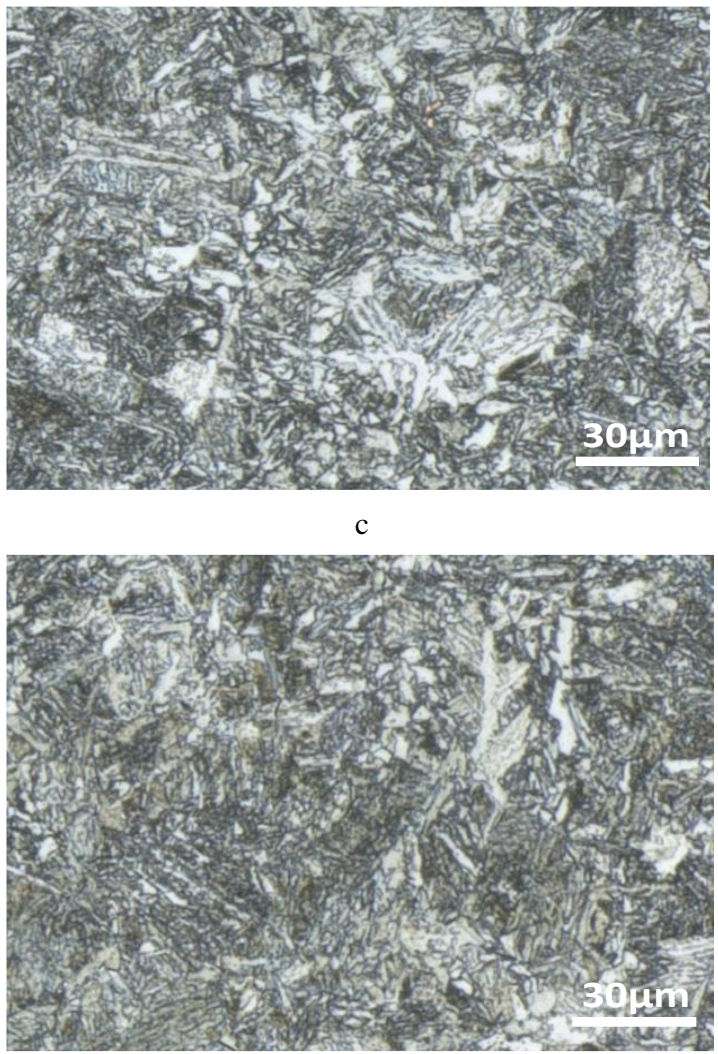

d

Fig. 4. Microstructures with different heat treatment conditions: $\mathrm{a}$-carburized layer with condition $\mathrm{A} ; \mathrm{b}$-carburized layer with condition $\mathrm{B}$; $\mathrm{c}$-central layer with condition $\mathrm{A}$; $\mathrm{d}$ - central layer with condition $\mathrm{B}$ 


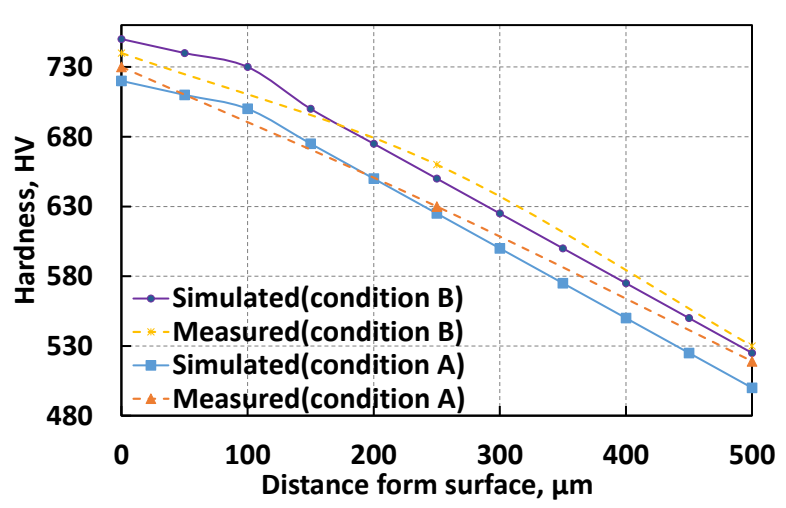

Fig. 5. Hardness distribution of specimens with different heat treatment conditions

\subsection{Residual stress}

Residual stresses at the surface of the specimens are measured using the X-ray diffraction stress analysis [21]. A diffractometer (Rigaku PSPC/MICRO stress analyzer) is used to produce $\mathrm{Cr}-\mathrm{K} \alpha \mathrm{X}$-ray radiation at a voltage of $30 \mathrm{kV}$ and an electric current of $30 \mathrm{~mA}$. The instrument uses a collimator with a diameter of $0.2 \mathrm{~mm}$.

The measuring point of residual stress is close to the notched tip. The directions of measurement are $\mathrm{X}$ direction, which are also shown in Fig. 3.

The residual stress distributions in the near surface layers of the test specimens are shown in Fig. 6. The measured results show good agreement with the simulated results. It can be observed that the maximum of the compressive residual stresses is about $200 \mu \mathrm{m}$ under the surface of the specimen and the value is about - 560 MPa. With increasing depth, the compressive residual stresses are decreased gradually. The depth of the compressive residual stress zone is up to $2000 \mu \mathrm{m}$. It can be conclude that the residual stress of carburized layer and subsurface with condition B are both greater than that with condition A. It can be considered that more compressive residual stress with condition $\mathrm{B}$ is more beneficial for improving the fatigue strength than that by condition $\mathrm{A}$.

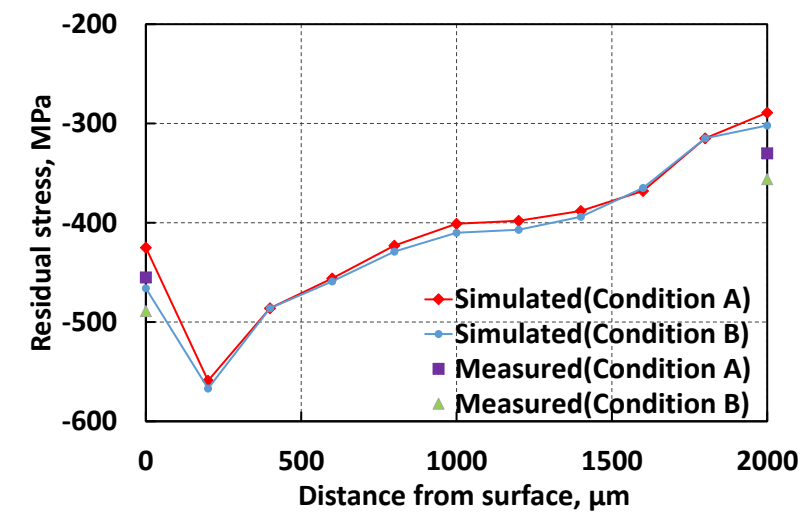

Fig. 6. Residual stress distribution of specimens with different heat treatment conditions

\subsection{Domain size}

According to the integral breadth of ferrite $\{211\}$ peak, domain size is obtained via Voigt method [22, 23]. The relationship of measured profile, the structurally broadened profile and the instrumental profile is shown in Eq. 1.
$\beta_{C}^{h}=\beta_{C}^{f}+\beta_{C}^{g}, \beta_{G}^{h^{2}}=\beta_{G}^{f^{2}}+\beta_{G}^{g^{2}}$,

where $\beta_{C}^{h}, \beta_{C}^{f}$ and $\beta_{C}^{g}$ denote the Cauchy components half width of measured profile, the structurally broadened profile and the instrumental profile respectively. $\beta_{G}^{h}$ and $\beta_{G}^{g}$ denote the Gaussian components half width of measured profile and the instrumental profile respectively.

After deconvolution, domain sizes $(D)$ is calculated via the following formulas. The Scherrer equation can be written as:

$D=\lambda /\left(\beta_{C}^{f} * \cos \theta\right)$,

where $\theta$ is the diffraction angle and $\lambda$ is the wavelength of the incident X-ray.

The diffraction pattern with different conditions in the case of X-ray incident angle $\psi=0^{\circ}$ is depicted in Fig. 7. The domain sizes of the specimens with different conditions are shown in Table 2. It can be proved that the heat treatment process can refine the domain of the specimens and optimized condition can obtain finer domain. It can be considered that condition B with smaller domain size is more beneficial to improve the fatigue strength than condition A.

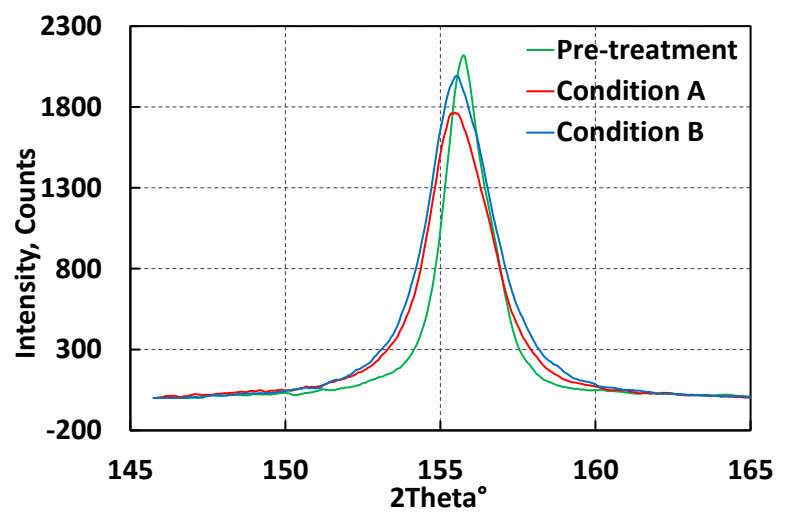

Fig. 7. X-ray diffraction spectra and half width

Table 2. Domain size of specimens with different conditions

\begin{tabular}{|c|c|c|c|}
\hline & Pre-treatment & Condition A & Condition B \\
\hline Domain size & $31.7 \mu \mathrm{m}$ & $22.7 \mu \mathrm{m}$ & $21.6 \mu \mathrm{m}$ \\
\hline
\end{tabular}

\subsection{Fatigue behavior}

The test specimens with various states (original, the carburized layer, subsurface layer and central layer) were tested completely in tension-tension mode at the room temperature until fracture. In this study, load control $\left(R=S_{\min } / S_{\max }=0.1\right)$ using a sinusoidal waveform at $10 \mathrm{~Hz}$ is conducted for all testing. A Shimadzu servo-hydraulic fatigue test machine (15 kN force and $25 \mathrm{~mm}$ displacement capacities) with in situ observation by JSM-5410LV scanning microscope was used for all testing.

The fatigue limit of the specimens with different conditions are shown in Fig. 8. Comparing with the fatigue limit of original microstructure, it can be proved that the fatigue limits of different layers of specimens with heat treatment are improved with different extents. After carburizing and quenching, the fatigue strength of the central layer is better than that of the subsurface layer and the fatigue strength of the subsurface layer is better than that 
of the carburized layer. This is because of the different microstructure distribution shown in Fig. 4. Comparing with condition $\mathrm{A}$, the condition $\mathrm{B}$ has a greater improvement of fatigue strength all in carburized layer, subsurface layer and central layer. Based on previous analysis, it proves that the joint action of microstructure, domain refinement and compressive residual stress results in the strengthening mechanism.

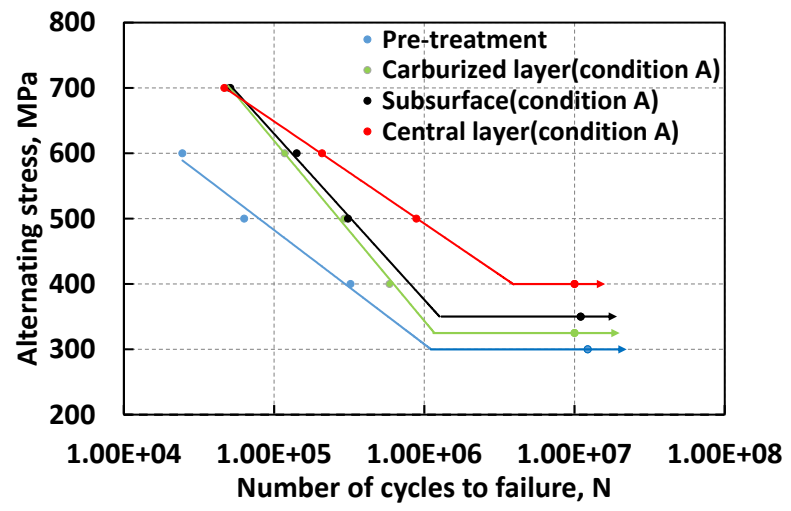

a

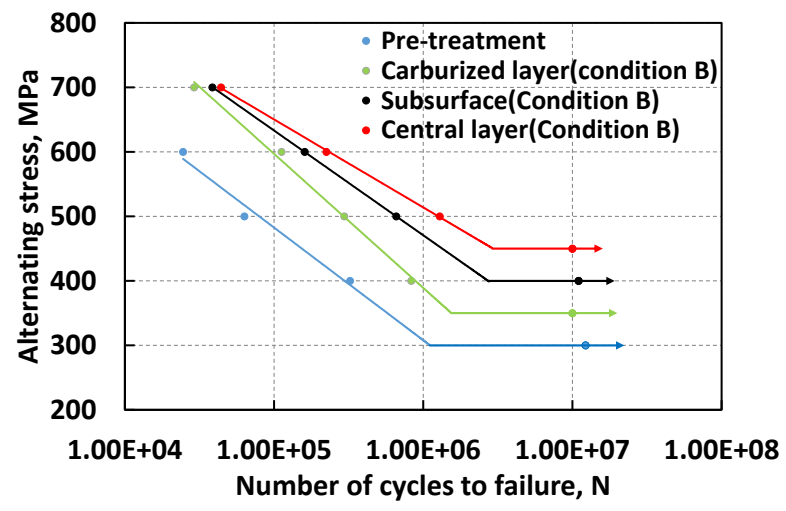

b

Fig. 8. S-N curves of the specimens with heat treatment conditions: $\mathrm{a}$-condition $\mathrm{A} ; \mathrm{b}-$ condition $\mathrm{B}$

\subsection{Fatigue crack growth}

The SEM photographs of crack length with different cycles are shown in Fig. 9. Fig. 9 a is the crack of the initial stages with 977857 cycles, and Fig. $9 \mathrm{~b}$ is the crack of the late stages with 1029507 cycles.

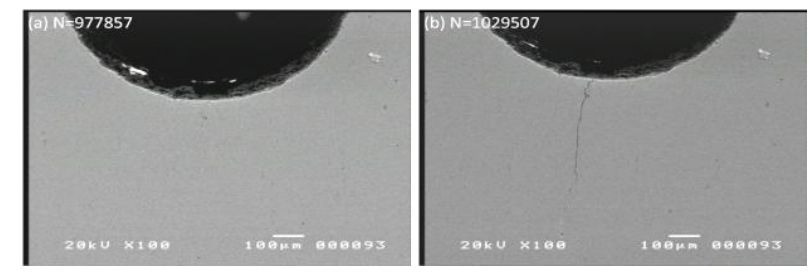

Fig. 9. SEM photographs of crack length of specimen with different cycles: $\mathrm{a}-\mathrm{N}=977857$; $\mathrm{b}-\mathrm{N}=1029507$

Crack length versus number of fatigue cycles for carburized layer with $500 \mathrm{MPa}$ stress level is shown in Fig. 10 a. In order to characterize the crack growth behavior, the stress intensity range $\Delta \mathrm{K}$ and the crack length per cycle $d a / d N$ were computed, and the crack growth rate curves are plotted in Fig. 10 b. It can be observed that the crack initiation and the crack propagation rate of condition $B$ is slower than that of condition A.


Fig. 10. Initiation of crack and crack growth rate for carburized layer: a-crack length versus number of fatigue cycles; $\mathrm{b}-d a / d N$ versus $\Delta K$

It is because the residual stress of specimen with condition B is larger and the domain size is smaller. It is noteworthy that when the legth of crack is $200 \mu \mathrm{m}$, the crack growth rate becomes slower. This is because the maximum of the compressive residual stresses is about $200 \mu \mathrm{m}$ under the surface of the specimens. It is verified that the compressive residual stress has a great influence on the fatigue performance.

As shown in Fig. $11 \mathrm{a}$ and Fig. 11 b, since the residual stress of specimen is larger, it can clearly be seen that the condition B tends to delay initiation of crack, and the crack growth life increased by 100 percent. Combining previous analysis, it is verified that the compressive residual stress and domain refinement have a great influence on the fatigue performance.

As shown in Fig. $12 \mathrm{a}$ and Fig. 12 b, since the residual stress is almost the same, the crack is simultaneously generated. It can be proved that crack growth rate with condition B is slower due to domain refinement.

In summary, it proves that the joint action of domain refinement and compressive residual stress results in the strengthening mechanism of carburized layer and subsurface. The domain refinement results in the strengthening mechanism of central layer. The fatigue strengthening effect with condition B is better than that with condition A. 


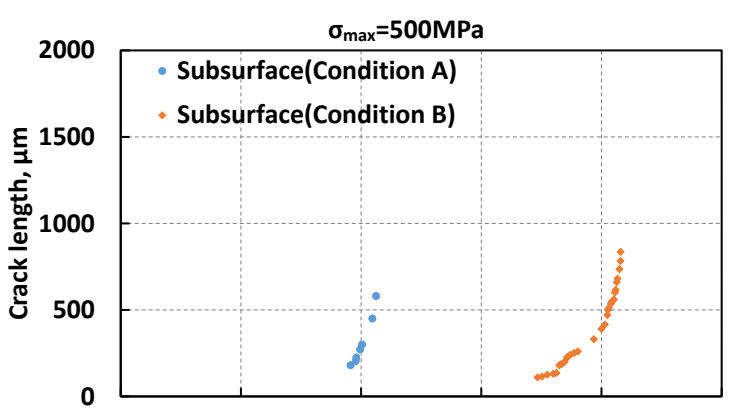

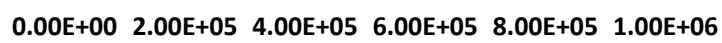
$\mathrm{N}$, cycles

a

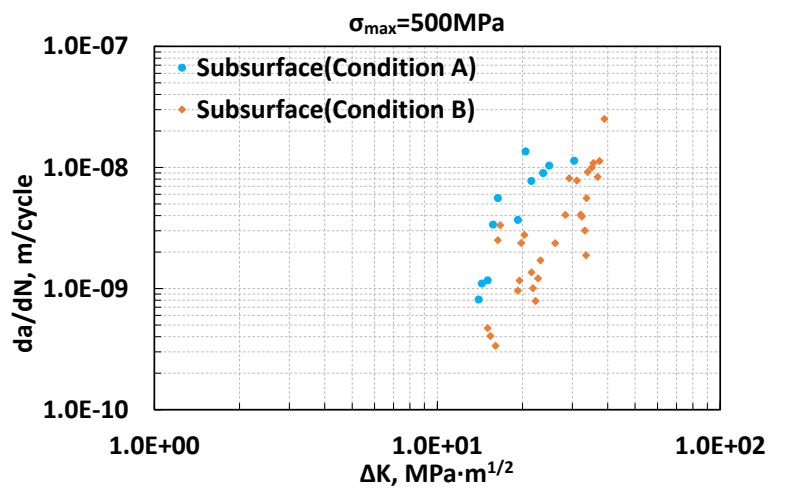

b

Fig. 11. Initiation of crack and crack growth rate for subsurface layer: a-crack length versus number of fatigue cycles; $\mathrm{b}-d a / d N$ versus $\Delta K$

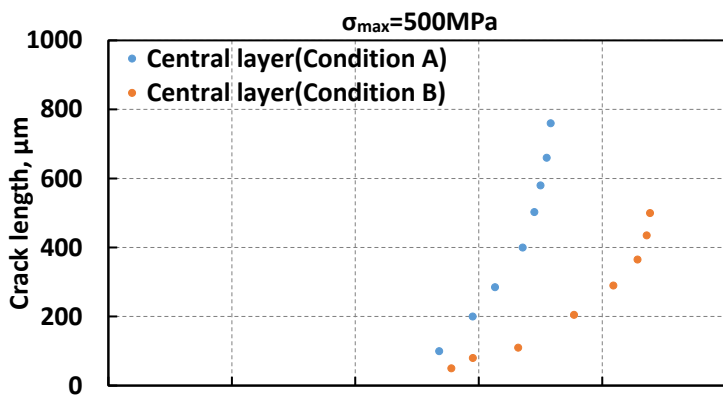

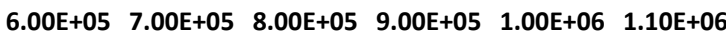
$\mathrm{N}$, cycles

a

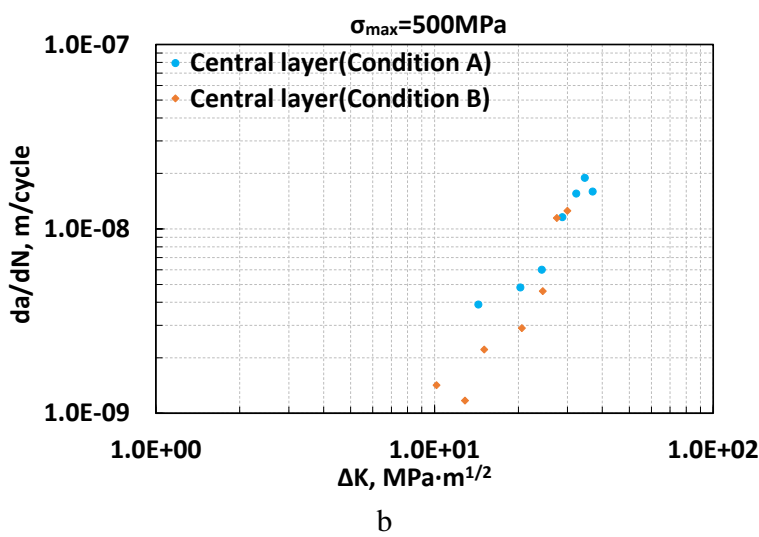

Fig. 12. Initiation of crack and crack growth rate for central layer: a-crack length versus number of fatigue cycles; $\mathrm{b}-d a / d N$ versus $\Delta K$

\section{CONCLUSIONS}

The fatigue life of carburized parts is great significance for the engineering design. In the present work the improvement of fatigue performance and strengthening mechanism with different conditions are discussed in detail. The following conclusions can be drawn as:

1. It is proved that the fatigue performance of different layers of specimens with heat treatments are improved with different extents. The optimization condition has better reinforcing effect;

2. Condition $\mathrm{B}$ results in higher compressive residual stress, smaller domain size and less retained austenite;

3. The surface hardness with condition B is higher due to the smaller volume fraction of retained austenite;

4. The joint action of domain refinement, compressive residual stress and microstructure result in the strengthening mechanism of fatigue performance. Where, the joint action of domain refinement and compressive residual stress results in the strengthening mechanism of carburized layer and subsurface layer. The domain refinement results in the strengthening mechanism of central layer.

\section{Acknowledgment}

This work was supported by Introduction of foreign intelligence projects in Hebei and High-Tech Research Center in Saitama Institute of Technology in Japan.

\section{REFERENCES}

1. Boniardi, M., D'Errico, F., Tagliabue, C. Influence of Carburizing and Nitriding on Failure of Gears - A Case Study Engineering Failure Analysis 13 (3) 2006: pp. 312-339. https://doi.org/10.1016/j.engfailanal.2005.02.021

2. Genel, K., Demirkol, M. Effect of Case Depth on Fatigue Performance of Aisi 8620 Carburized Steel International Journal of Fatigue 21 (2) 1999: pp. 207-212. https://doi.org/10.1016/S0142-1123(98)00061-9

3. Srinivasan, R., Natarajan, S., Sivakumar, V.J. Fatigue Life Improvement on 20MnCr5 Steel through Surface Modification for Auto Transmission Application Archives of Civil and Mechanical Engineering 19 (2) 2019: pp. $360-374$. https://doi.org/10.1016/j.acme.2018.11.005

4. Nojima, K., Ogata, K., Tanaka, M., Nishi, R., Ono, Y., Koide, T. Bending Fatigue Strength of Case-Carburized Helical Gears (In the Case of Large Helix Angles) Journal of Mechanical Science and Technology 31 (12) 2017: pp. $5657-5663$. https://doi.org/10.1007/s12206-017-1106-0

5. Zhang, J., Zhang, Q., Wu, C., Xu, Z., Lyu, S. Experimental Application of Pitting Formation for $20 \mathrm{MnCr} 5$ Carburized Gear Tooth International Journal of Precision Engineering and Manufacturing 15 (5) 2014: pp. 899-903. https://doi.org/10.1007/s12541-014-0415-9

6. Wang, W., Liu, H., Zhu, C., Bocher, P., Liu, H., Sun, Z. Evaluation of Rolling Contact Fatigue of a Carburized Wind Turbine Gear Considering the Residual Stress and Hardness Gradient Journal of Tribology 140 (6) 2018: pp. 1-10. https://doi.org/10.1115/1.4040052

7. Chen, Z.K., Zhou, T., Zhao, R.Y., Zhang, H.F., Lu, S.C., Yang, W.S., Zhou, H. Improved Fatigue Wear Resistance of 
Gray Cast Iron by Localized Laser Carburizing Materials Science and Engineering: A 644 2015: pp. 1-9. https://doi.org/10.1016/j.msea.2015.07.046

8. Jo, B., Sharifimehr, S., Shim, Y., Fatemi, A. Cyclic Deformation and Fatigue Behavior of Carburized Automotive Gear Steel and Predictions Including Multiaxial Stress States International Journal of Fatigue 100 (2) 2017: pp. $454-465$. https://doi.org/10.1016/j.ijfatigue.2016.12.023

9. Nejad, R.M., Farhangdoost, K., Shariati, M. Numerical Study on Fatigue Crack Growth in Railway Wheels under the Influence of Residual Stresses Engineering Failure Analysis 52 2015: pp. 75-89.

https://doi.org/10.1016/j.engfailanal.2015.03.002

10. Asi, O., Can, A.Ç., Pineault, J., Belassel, M. The Relationship between Case Depth and Bending Fatigue Strength of Gas Carburized Sae 8620 Steel Surface and Coatings Technology 201 (12) 2007: pp. 5979-5987. https://doi.org/10.1016/j.surfcoat.2006.11.006

11. Farivar, H., Deepu, M.J., Hans, M., Phanikumar, G., Bleck, W., Prahl, U. Influence of Post-Carburizing Heat Treatment on the Core Microstructural Evolution and the Resulting Mechanical Properties in Case-Hardened Steel Components Materials Science and Engineering: A 744 2019: pp. $778-789$. https://doi.org/10.1016/j.msea.2018.12.061

12. Yin, D., Liu, H., Chen, Y., Yi, D., Wang, B., Wang, B., Shen, F., Fu, S., Tang, C., Pan, S. Effect of Grain Size on Fatigue-Crack Growth in 2524 Aluminium Alloy International Journal of Fatigue 84 2016: pp. 9-16. https://doi.org/10.1016/j.ijfatigue.2015.11.011

13. Hu, D., Mao, J., Song, J., Meng, F., Shan, X., Wang, R. Experimental Investigation of Grain Size Effect on Fatigue Crack Growth Rate in Turbine Disc Superalloy Gh4169 under Different Temperatures Materials Science and Engineering: A 669 2016: pp. 318-331. https://doi.org/10.1016/j.msea.2016.05.063

14. Mukai, R., Matsumoto, T., Ju, D.Y., Suzuki, T., Saito, H., Ito, Y. Modeling of Numerical Simulation and Experimental Verification for Carburizing-Nitriding Quenching Process Transactions of Nonferrous Metals Society of China 16 2006: pp. s566-s571. https://doi.org/10.1016/s1003-6326(06)60257-4

15. Zhang, X., Tang, J.Y., Zhang, X.R. An Optimized Hardness Model for Carburizing-Quenching of Low Carbon Alloy Steel Journal of Central South University 24 (1) 2017: pp. 9-16. https://doi.org/10.1007/s11771-017-3403-2

16. Kim, N.K., Bae, K.Y. Analysis of Deformation in the Carburizing-Quenching Heat Treatment of Helical Gears Made of Scm 415h Steel International Journal of Precision Engineering and Manufacturing 16 (1) 2015: pp. $73-79$. https://doi.org/10.1007/s12541-015-0009-1

17. Enloe, C.M., Findley, K.O., Speer, J.G. Austenite Grain Growth and Precipitate Evolution in a Carburizing Steel with Combined Niobium and Molybdenum Additions Metallurgical and Materials Transactions A 46 (11) 2015: pp. 5308-5328.

https://doi.org/10.1007/s11661-015-3103-1

18. Miao, S., Ju, D., Chen, Y., Liu, Y. Optimization Based on Orthogonal Experiment Design and Numerical Simulation for Carburizing Quenching Process of Helical Gear Materials Performance and Characterization 7 (6) 2018: pp. 1-14. https://doi.org/10.1520/MPC20180019

19. Ju, D.Y., Inoue, T. On the Material Process Simulation Code Cosmap- Simulated Examples and Its Experimental Verification for Heat Treatment Process Key Engineering Materials 345-346 2007: pp. 955-958. https://doi.org/10.4028/www.scientific.net/KEM.345346.955

20. Colaço, R., Vilar, R. On the Influence of Retained Austenite in the Abrasive Wear Behaviour of a Laser Surface Melted Tool Steel Wear $258(1-4)$ 2005: pp. 225-231. https://doi.org/10.1016/j.wear.2004.09.029

21. Ju, D.Y., Han, B. In-Situ Observation of Dislocation and Analysis of Residual Stresses by Fem/Ddm Modeling in Water Cavitation Peening of Pure Titanium IOP Conference Series: Materials Science and Engineering 82 2015: pp. 1-9. https://doi.org/10.1088/1757-899x/82/1/012115

22. Vives, S., Gaffet, E., Meunier, C. X-Ray Diffraction Line Profile Analysis of Iron Ball Milled Powders Materials Science and Engineering: A 366 (2) 2004: pp. 229-238. https://doi.org/10.1016/s0921-5093(03)00572-0

23. Luan, W., Jiang, C., Wang, H., Panardie, J., Chen, D. XRD Investigation of Thermostability of $\mathrm{TiB}_{2} / \mathrm{Al}$ Deformation Layer Introduced by Shot Peening Materials Science and Engineering: A 480 (1-2) 2008: pp. $1-4$. https://doi.org/10.1016/j.msea.2007.07.004 